\title{
Merleau-Ponty, Lefort e a Modernidade como problema filosófico ${ }^{1}$
}

\author{
Bernard Flynn \\ The New School for Social Research \\ Tradução: \\ Silvana de Souza Ramos e Lucas Carpinelli
}

\section{RESUMO}

$\mathrm{Na}$ primeira parte deste artigo, apresentarei, de forma breve, a concepçấo de Modernidade de Robert Pippin e por que ele a considera um problema filosófico. Mostrarei como determinados filósofos - Kant, em especial - a conceituaram e entáo voltar-me-ei a Hegel, cuja posição, em versão radicalmente deflacionária, o próprio Pippin sustenta. $\mathrm{Na}$ segunda parte, abordarei aspectos da filosofia de Merleau-Ponty que contestam a espontaneidade da consciência, noção central para o hegelianismo de Pippin. Na terceira parte, concluirei com uma discussão da obra de Lefort, sua prática de hiper-reflexão e sua própria teorização da Democracia e do Totalitarismo. Sustento que, comparativamente, a ontologia de Merleau-Ponty e a filosofia política de Lefort apresentam maior capacidade de produzir reflexóes sobre a Modernidade sem apelo a qualquer tipo de estrutura teleológica ou teológica.

\section{PALAVRAS-CHAVE}

Modernidade; Pippin; Lefort; Merleau-Ponty; Democracia.

\begin{abstract}
In the first part of this paper, I will briefly present what Robert Pippin conceives Modernity to be, and why he thinks it is a philosophical problem. I will show how a number of philosophers have conceptualized it, most notably Kant and then I will turn to Hegel, whose position, in a radically deflationary version, Pippin himself supports. In the second part, I will turn to aspects of Merleau-Ponty's philosophy that contest the spontaneity of consciousness, which is central to Pippin's Hegelianism. In the third part, I will conclude by turning to the work of Lefort, his practice of hyper-reflection, and his own theory of Democracy and Totalitarianism. I contend that the ontology of Merleau-Ponty and the political philosophy of Lefort are more capable of thinking Modernity outside of any teleological or theological framework.
\end{abstract}

\section{KEY WORDS}

Modernity; Pippin; Lefort; Merleau-Ponty; Democracy.

\footnotetext{
1 Eu gostaria de agradecer ao Departamento de Filosofia da Universidade de São Paulo pelo convite para participar do "Congresso Internacional Merleau-Ponty: Crítica e Contemporaneidade". Claude Lefort era meu amigo e falava com frequência e ternura sobre o período que passou na cidade de São Paulo; visitá-la deixoume muito feliz. Gostaria de agradecer também aos tradutores, por permitirem que eu me enderece a leitores de língua portuguesa
} 
O título deste artigo faz referência óbvia ao devidamente celebrado Modernism as a Philosophical Problem, de Robert B. Pippin (1999). O que me proponho a fazer na primeira parte deste artigo é apresentar um breve esboço do argumento de Pippin, sua concepção da Modernidade e por que ele a considera um problema filosófico. Mostrarei como determinados filósofos - Kant, em especial - a conceituaram e então voltar-me-ei a Hegel, cuja posição, em versão radicalmente deflacionária, o próprio Pippin sustenta. Ele tece considerações sobre dois críticos específicos da Modernidade, a bem dizer, Nietzsche e Heidegger. Neste artigo, no entanto, náo seguirei esse aspecto de seu trabalho. $\mathrm{Na}$ introdução à segunda edição de seu livro ele nos conta (Ibid., p. xi-xii) que a abordagem de Nietzsche e Heidegger presente no texto de 1991 se deveu ao fato de o teatro europeu da Modernidade exibir, à época, um descontentamento muito mais forte com a Modernidade do que o dos Estados Unidos, onde, em termos gerais, permanecíamos alegres modernistas liberais. Esse não é mais o caso. Ideias antimodernas, autoritárias, nativistas e racistas emergiram em todo o mundo e, é claro, estão encarnadas no valentáo que atualmente ocupa a Casa Branca dos Estados Unidos, um nacionalista branco. Repensar a Modernidade, portanto, é algo muito necessário e o trabalho de Pippin avança a passos largos nesse sentido.

$\mathrm{Na}$ segunda parte deste artigo, abordarei aspectos da filosofia de Merleau-Ponty que contestam a espontaneidade da consciência, noção central para o hegelianismo de Pippin. Há muito a dizer sobre esses aspectos da filosofia de Merleau-Ponty; contudo, a fim de não exceder o espaço de que disponho, irei apenas evocar certas dimensóes de seu pensamento, sem dar a elas elaboraçáo extensiva. Na terceira parte, concluirei com uma discussão da obra de Lefort, sua prática de hiper-reflexão e sua própria teorização da democracia e do totalitarismo. Sustento que, comparativamente, a ontologia de Merleau-Ponty e a filosofia política de Lefort apresentam maior capacidade de produzir reflexóes sobre a Modernidade sem apelo a qualquer tipo de estrutura teleológica ou teológica.

I.

Como descrever a Modernidade? Para Pippin, na esteira de Kant, o aspecto central da Modernidade é sua reivindicaçáo por autonomia. A Modernidade intenciona sair de sua condição de, nas palavras de Kant, "menoridade autoinfligida". Como veremos, no entanto, a partir de Hegel não é tão claro que tal menoridade seja de fato autoinfligida. O Esclarecimento é, para Kant, a capacidade de pensar de modo autônomo. É uma forma de vida, uma maneira de ser no mundo.

Em um subcapítulo intitulado "The Kantian Enlightenment" (Pippin, 1999, p. 45-49), Pippin argumenta que a filosofia de Kant é mais consistente do que qualquer outra com o entendimento que a Modernidade tem de si mesma como, em termos 
gerais, uma orientação em filosofia, um começo não limitado pela tradição ou pela autoridade religiosa, firmemente livre e independente e, portanto, inteiramente autoconsciente no que toca às suas próprias possibilidades. Kant inaugurou, de modo radical e consistente, a ideia moderna de um novo começo autodeterminado. Tanto no registro da epistemologia quanto no da ética, Kant propóe uma filosofia baseada na autonomia. Não iremos revisitar os já muito conhecidos detalhes da teoria do conhecimento de Kant. Iremos apenas nos ater àqueles aspectos que têm relevância para a construção, por Pippin, de uma "Modernidade kantiana".

Para Kant, o conhecimento requer tanto a espontaneidade quanto a receptividade. A multiplicidade sensível é recebida sob as formas da sensibilidade, o espaço e o tempo. Ela é espontaneamente organizada pelo entendimento de acordo com as doze categorias derivadas da tábua de juízos possíveis. A atividade sintética do juízo é governada pela unidade transcendental da apercepção. Seguem-se disso duas consequências importantes. Em primeiro lugar, o conhecimento do mundo suprassensível (Deus, por exemplo) é impossível, por não possuirmos intuição intelectual. Em segundo lugar, temos conhecimento do mundo apenas na medida em que ele nos é dado através das formas da sensibilidade e organizado pelas categorias do entendimento. Assim, temos conhecimento dos fenômenos, mas não dos númenos, não do $\mathrm{X}$ Transcendente, a coisa-em-si. A unidade transcendental da apercepção é a sede da espontaneidade da mente e é o cerne de nossa capacidade de conferir sentido, de produzir significado. O primeiro passo é nos darmos conta de que o que esteve envolvido o tempo todo em nosso pensar, julgar e agir, ou seja, muito da forma que tomam nossa experiência e ação, é algo que "depende de nós", que não é determinado pelo que encontramos no mundo ou pelas paixóes da natureza humana. Nesses termos, a insistência moderna na autonomia pode ser defendida com grande eficácia.

Pippin interpreta a filosofia de Hegel como a radicalização de um aspecto da posição de Kant, a espontaneidade da mente, e como uma crítica de outro, a tábua das categorias. Kant "a um só tempo insistiu no ideal moderno de plena maturidade ou autossuficiência (um autofundar-se da razão) e tentou levá-lo a termo"; com o seu pensamento, "pode-se dizer que as dimensōes totais do problema filosófico da modernidade, se ainda carentes de resoluçáo, chegaram à sua expressão completa" (Ibid., p. 59). Pippin perguntará: a partir de Hegel, quão espontânea ela é? “[Embora] Kant possa ter alegado que a razão 'faz para si, com total espontaneidade, uma ordem segundo ideias', na teoria de Kant, tomada propriamente, a espontaneidade em questão é muito menos que 'total'. A espontaneidade do entendimento é restringida pelas formas da intuição humana, a espontaneidade da razão é restringida por uma arquitetura interna preexistente" (Ibid., p. 65). Ele descreve o projeto de Hegel, seu "experimento", como uma radicalização da tentativa de autofundamentação da filosofia 
crítica. Tenta fazer isso, porém, "sem qualquer apelo por garantia a intuições, fatos da razão ou formas lógicas” (Ibid.). Isso não significa dizer que Hegel negue a existência do mundo material ou do dado: a distinção entre o que é dado e o que fazemos com isso. Essa distinção é sempre articulada dentro de uma forma de consciência, dentro de uma figura de consciência. A questão é, simplesmente: se a mente organiza espontaneamente nossa experiência, dando-lhe sentido, e se ela não depende de um conjunto pré-existente de categorias, como ela faz isso? Como ela organiza nossa experiência, as regras que governam a formação de nossa estrutura de construçáo de sentido? Segundo Pippin e Hegel, ela o faz refletindo sobre um resultado sempre já presente de figuras anteriores de consciência.

Para Kant, as categorias são o produto de um sujeito transcendental que pensa sua própria unidade, a unidade da apercepção transcendental. Para Hegel, escreve Pippin, "não existe nada que se assemelhe a 'um tal sujeito'. Hegel se propóe a pensar a subjetividade humana coletiva e historicamente" (Ibid., p. 66). A estrutura dentro da qual conferimos sentido à nossa experiência não é um conjunto pré-dado de categorias, mas o produto de uma reflexão crítica, uma reflexão sobre estruturas anteriores de produção de sentido. Hegel descreve a autoconsciência emergente da comunidade como algo que critica a estrutura da doação de sentido por meio de um processo de autorreflexão crítica, em que as estruturas anteriores se mostram inadequadas - inadequadas, vale dizer, com base em seus próprios critérios. A imagem do conceito de Modernidade de Pippin pede no mínimo um vislumbre, se superficial e esquemático, de como ele e Terry Pinkard têm, em muitos aspectos, ideias semelhantes no que toca às suas interpretaçôes de Hegel (embora não seja minha intenção sugerir que suas posiçóes sejam idênticas). Há algo na interpretação padrão de Hegel que ambos contestam. Trata-se da ideia de que o Espírito é uma mente cósmica que aliena ou objetifica a si mesma e de que a fenomenologia é o processo pelo qual sua unidade perdida é recuperada, pelo qual ela retorna a si mesma em conhecimento absoluto. Em outras palavras, o Espírito seria uma secularização do conceito cristáo de Deus, enquanto seu autodesenvolvimento seria uma secularização da providência cristã. Se isso é Hegel, então, em minha opiniáo (e, penso eu, na de Pippin), a crítica a Hegel formulada por Karl Löwith em Meaning in History é verdadeiramente devastadora e devemos fazer o que muitos filósofos fizeram, isto é, simplesmente "seguir em frente".

Retornaremos, abaixo, à questão de se Pippin e Pinkard foram bem-sucedidos em exorcizar Deus da filosofia de Hegel. Se o Espírito não é Deus, o que é? Se cada forma da consciência é alcançada por meio de uma reformulação de formas prévias operada pela reflexão de uma comunidade sobre si mesma, e se Hegel rejeita uma tábua a-histórica de categorias, então é necessário que ele argumente em favor de uma concepção da subjetividade humana como radicalmente histórica. "É nesse 
sentido, um sentido que pressupõe um sujeito coletivo, ou mesmo uma instituição vista como sujeito, que se pode falar de 'autodeterminação' ou, ao menos, de 'não ser determinado por coisa alguma, a não ser' a tentativa do Espírito de corrigir suas próprias práticas" (Pippin, 1989, p. 153). O espírito não é um ser, não é Deus, mas sim uma comunidade refletindo sobre si mesma. É uma prática. É uma atividade. Agora, para encurtar uma longa e complicada história: o que é a Modernidade, segundo Pippin? Ela é o desfecho desse processo de autorreflexão; é o movimento, para evocar o vocabulário de Cornelius Castoriadis, a partir de uma concepçáo de nossas estruturas de produção de sentido como imbuídas de autoridade heteronomamente instituída - derivada de Deus, de deuses, da Natureza e assim por diante -, rumo ao reconhecimento de que nossa estrutura de doação de sentido e as instituiçôes fundamentais de nossa sociedade sáo o produto de nossa própria atividade, de nossa própria autonomia.

O movimento da Fenomenologia do Espírito se dá a partir da "consciência", na qual, alega-se, recebemos da experiência imediata a estrutura última de nosso conhecimento, a certeza sensível. A certeza sensível malogra segundo seus próprios critérios. Aquilo que se queria certo termina por se mostrar inefável; é algo de que, devido à "natureza divina" da linguagem, não se pode falar. Não pode, portanto, servir de fundamento para nosso conhecimento, e assim por diante até o conhecimento absoluto, que não é o reconhecimento do Espírito, sua reconciliação consigo mesmo, mas o conhecimento de que não há nada "mais alto" do qual possa advir a autoridade de seus critérios de produção de sentido. Pippin nunca diz isso, propriamente, mas o filósofo hegeliano alemão Gabriel Markus, raciocinando de maneira semelhante, sustenta que o conhecimento absoluto é o ateísmo. Em seu livro Hegel on Self-Consciousness, Pippin mostra de maneira muito convincente que o movimento da consciência para a autoconsciência na Fenomenologia do Espírito é um movimento que parte de uma concepçáo cartesiana da consciência enquanto presença imanente a si mesma em direção à consciência como desejo e, em última instância, ao desejo por reconhecimento; movimento, portanto, que vai de uma concepção monológica para uma concepção essencialmente intersubjetiva de consciência. Isso é essencial caso se queira conceber o Espírito como "um sujeito coletivo, ou mesmo uma instituição vista como sujeito".

A interpretação de Pippin da dialética do senhor e do escravo não a tem como dois indivíduos que confrontam um ao outro, como é o caso na narrativa de Sartre sobre aquele que espia pelo buraco da fechadura e aquele que o flagra (Sartre, 1997, p. 33438), mas como dois regimes diferentes de produção de sentido em busca de reconhecimento. A Modernidade, como disse Kant, é a saída da condição de tutelagem. Porém, seria tal tutelagem de fato autoinfligida e será mesmo que requer nada além de 
coragem, de um ousar saber, para que a transcendamos? Para Hegel, não é esse o caso. Deixá-la para trás requer uma longa jornada, "o caminho da dúvida ou, com mais propriedade, caminho de desespero" (Hegel, 2003, $\$ 78$, p. 74). Em Modernism as a Philosophical Problem, Pippin afirma que a Modernidade, tomada em si, não é uma revolução, nem autóctone, nem absolutamente autossustentada ou autofundante. "[É] a história humana como um todo que deve ser vista como 'absolutamente' autossustentada ou autofundante, e a modernidade é apenas o começo da realização final [da] própria autoconsciência, bem como a realização de um telos já implícito na origem da experiência ocidental" (Pippin, 1999, p. 70). Em um único parágrafo, Pippin consegue falar da história humana como um todo e de um telos implícito na origem da experiência ocidental. Como pode toda a história humana ser entendida com base no telos implícito na origem da experiência ocidental? Pippin e Pinkard têm plena ciência desse problema. Na página seguinte, Pippin continua:

Somos uma vez mais levados de volta à questáo de se deveríamos considerar quaisquer instituiçóes modernas desse tipo como mais do que inteiramente contingentes, como realmente produtos de alguma espécie de processo histórico, ou mesmo racional, autotransformador e autocorretivo. Esse é obviamente o aspecto mais implausível da alegação de Hegel (Ibid., p. 71).

Em seguida, Pippin considera a possibilidade de que as mudanças na história humana sejam contingentes e, portanto, "não sejam subsumíveis a qualquer narrativa única" (Ibid., p. 72). Ele imediatamente rejeita essa possibilidade, por acarretar um tipo rortyano de relativismo. Na parte três deste artigo, veremos como esse não é necessariamente o caso.

Pippin nos diz que se pode chegar a uma versão mais fraca ou mais forte da teleologia com base nessas reflexões. O próprio Hegel chegou a uma versão muito forte. Pippin, por sua vez, claramente favorece a versão mais fraca, "um tipo de versão 'historicamente situada' da racionalidade ou da explanação racional; a produção de sentido, em termos gerais" (Ibid., p. 75). No entanto, a questão que desejo colocar é: à luz do sistema conceitual herdado de Kant e Hegel, estaria a versão mais fraca realmente aberta a Pippin? Afinal, se a força motora da dialética é a espontaneidade da consciência; se, ademais, a espontaneidade da consciência é verdadeiramente uma capacidade trans-histórica da mente humana como tal; e se, finalmente, as instituições ocidentais são o desfecho da dialética, como então podemos evitar uma versão mais forte da teleologia? A situação em que nos encontramos é tal que nos vemos obrigados a perguntar - como fez Terry Pinkard, de modo semelhante, em seu recente livro Does History Make Sense? - "teriam os não europeus fracassado em ser europeus ou seriam eles europeus imaturos?”. Ele rejeita essa ideia, é claro, e 
prontamente admite serem eurocêntricas ou, pior, racistas as Liçöes sobre a filosofia da história, de Hegel. A questão é: pode-se sair dessa ideia com o aparato conceitual que opera dentro da Modernidade enquanto problema filosófico? Nas palavras de Pippin, o "fracasso original da autoconsciência" é "uma incapacidade original de compreender o caráter autodeterminado da história humana e suas instituiçóes e, portanto, uma incapacidade de justificar reflexivamente tais instituiçôes ou defendêlas de ataques céticos" (Ibid., p. 70).

No entanto, devemos nos perguntar: o que poderia motivar uma consciência caracterizada pela espontaneidade a não reconhecer seus próprios produtos como seus, de fato? Essa noção de espontaneidade, herdada de Kant, será o foco de minha reflexão crítica, a qual valer-se-á de recursos conceituais da ontologia de Merleau-Ponty e da filosofia política de Lefort. Antes de prosseguir, porém, gostaria de me voltar brevemente ao trabalho de um ex-aluno de Lefort e Castoriadis, Marcel Gauchet. Em seu livro The Disenchantment of the World, Gauchet afirma que a origem da noção de que nossos sistemas de significado são instituídos a partir de outro lugar, isto é, heteronomamente instituídos, não resulta de um fracasso do entendimento, mas do temor que inspiram as perspectivas de proliferação de significado e de fracasso em se alcançar qualquer tipo de coesão social. "Esse paradoxo fundamental contém a chave de toda a nossa história, pois a essência da religiáo consiste tanto em alcançar a posse de si por meio do consentimento à despossessão, por meio do abandono do objetivo de dominar a natureza, quanto em legislar por nós em prol de outro objetivo, a bem dizer, o de garantir uma identidade definida e controlada a cada passo" (Gauchet, 1997, p. 3). A religiáo nos despoja de nossa capacidade de criar significado de modo a garantir que um grupo possa ter uma única estrutura de significado e que tal estrutura seja pensada como instituída desde outro lugar. Ao limitar a produção de significados, um grupo ganha identidade definida. Sirvo-me de Gauchet para mostrar que a origem da heteronomia, de uma teleologia heterônoma, não é um mal-entendido que poderia ser eliminado pelo conhecimento, mas uma "escolha política" que pode ser, não digo eliminada, mas modificada em nossa história política.

\section{II.}

Como eu disse, indicarei agora apenas alguns temas da filosofia de Merleau-Ponty que contestam a noção da espontaneidade da consciência, noção essa que, como espero ter demonstrado, é essencial para a concepção hegeliana de Pippin da Modernidade e que, como argumentei, leva-nos em direção a algo que não lhe interessa, isto é, a uma versão mais forte da teleologia. Permitam-me começar com a alegação de que nem Merleau-Ponty nem Lefort aceitariam uma concepção da Modernidade como autofundação. No posfácio de $O$ visivel e o invisivel, Lefort capta bem o 
espírito básico da filosofia de Merleau-Ponty em uma citação de Kafka, que dizia que as coisas se apresentavam a ele "não pelas raízes, mas por um ponto qualquer situado no meio" (Lefort, 1971, p. 261). Seria possível ver a totalidade da obra de Merleau-Ponty como uma crítica prolongada da noção de consciência como pura espontaneidade. Em A estrutura do comportamento, ele pergunta, retoricamente: seria a resposta simplesmente um retorno ao pensamento crítico? Não é o caso, como o evidencia o título do último capítulo dessa obra, "Não há uma verdade do naturalismo?". Para ele, tampouco se trata de um simples retorno ao naturalismo, mas sim de uma reformulação da "verdade do naturalismo".

Parece-me que a Fenomenologia da percepçâo envolve uma tensão entre, por um lado, sua apropriação de categorias fundamentais da filosofia de Husserl, que Merleau-Ponty e eu consideramos idealista, ainda que se trate, como ele afirma em "O Filósofo e sua Sombra”, de um idealismo perturbado desde dentro; e, por outro lado, sua concepção do significado como corporificado, não apenas no sentido de ter envolvimento do corpo, mas de ser embutido no que ele mais tarde chamaria de "a carne do mundo". Essa tensão se revela em seu tratamento da redução fenomenológica no "Prefácio". Ele argumenta que a verdade da redução é que ela não pode ser concluída. Para Husserl, na esteira de Descartes, a redução implica a constituição da transcendência no interior da imanência. Nas palavras de Merleau-Ponty: "Quando Descartes nos diz que a existência das coisas visíveis é duvidosa, mas que nossa visão, considerada como simples pensamento de ver, não o é, essa posição não é sustentável” (MerleauPonty, 1999, p. 501). Nós somos demasiadamente do mundo, de seu estofo, para que este se torne simplesmente o objeto intencional de um ato consciente. A percepção náo apreende a si mesma em um momento de certeza apodítica, mas "em uma espécie de ambiguidade e de obscuridade, já que ela não se possui e, ao contrário, se dissipa na coisa vista" (Ibid., p. 503). Essa rejeição da ideia da consciência como imanente a si mesma pode ser vista como um ponto concordante entre Hegel, Pippin e MerleauPonty em relação ao movimento da consciência para a autoconsciência na Fenomenologia do Espírito. Isso, no entanto, os leva a direçôes diferentes. No caso de Hegel, leva-o à consciência como desejo e, em última instância, a um desejo por reconhecimento; no de Merleau-Ponty, leva-o à nossa inelutável e ambígua inerência às coisas do mundo. Na sequência, apontarei outro aspecto do pensamento de Merleau-Ponty que contesta a espontaneidade da consciência.

Permitam-me citar uma longa passagem da Fenomenologia da percep̧̧ão.

Toda percepção acontece em uma atmosfera de generalidade e se dá a nós como anônima. Não posso dizer que eu vejo o azul do céu no sentido em que digo que compreendo um livro ou, ainda, que decido consagrar minha vida às matemáticas. [...] Toda vez que experimento uma sensação, sinto que ela 
diz respeito não ao meu ser próprio, aquele do qual sou responsável e do qual decido, mas a um outro eu que já tomou partido pelo mundo, que já se abriu a alguns de seus aspectos e sincronizou-se a eles. Entre minha sensação e mim há sempre a espessura de um saber originário que impede minha experiência de ser clara para si mesma. (Ibid., p. 290-91).

Na percepção, descubro um sentido que não constituí. Essa alteridade no interior da ipseidade é bem expressa por Rudolf Bernet: "A natureza é algo no coração da existência humana que não pertence propriamente ao sujeito humano: um fundamento (Grund) de suas capacidades constituintes que é, ao mesmo tempo, não fundamento ou abismo (Abgrund)" (Bernet, 1993, p. 57). Esse tema de uma passividade irredutível reaparecerá ao longo da evolução do pensamento de Merleau-Ponty sobre a linguagem, desde a Fenomenologia da percepção até "A linguagem indireta e as vozes do silêncio". No capítulo sobre a linguagem na Fenomenologia da percepção, Merleau-Ponty estabelece distinção entre uma fala falante e uma fala falada. A última é a sedimentação da fala falante. A fala falante é uma linguagem primordial que expressa a essência emocional de nossa experiência do mundo, uma linguagem motivada pela experiência direta. Depois de travar contato com a linguística estrutural de Saussure, ele passaria a rejeitar essa noção. Como escreve em A Prosa do mundo: "Todos veneramos secretamente esse ideal de uma linguagem que, em última análise, nos livraria dela mesma ao nos entregar às coisas" (Merleau-Ponty, 2007, p. 30), isto é, o ideal de uma linguagem munida de palavras outrora capazes de plena aderência aos objetos em si. Essa idade de ouro da linguagem é precisamente o que ele propôs, no capítulo sobre a linguagem em a Fenomenologia da percepção, com a ideia de fala falante. O encontro com Saussure revela a Merleau-Ponty o caráter errôneo de concepçóes dessa espécie e tem um efeito de longo alcance sobre seu pensamento, ao introduzir a noção de lateralidade à sua filosofia. O significado não emerge do sujeito, não está na superfície do letreiro da mesma forma como a manteiga está na superfície de uma fatia de pão. O significado emerge do espaçamento entre os signos. Há uma relação lateral entre os signos.

Para Saussure, a relação entre o significante e o significado é arbitrária, no sentido de que não há relação natural ou motivada entre eles. Como a caracteriza o linguista suíço, "na língua há apenas diferenças sem termos positivos" (Saussure, 1977, p. 139). Embora seja verdade que a relação entre significante e significado seja arbitrária, não é verdade que o seja a relação dos signos entre si. Esta não é análoga à relação que existe entre uma pessoa e seu número de telefone. Há uma relação interna entre os signos tomada como se ocorresse no interior de um todo articulado, no interior do significado tomado como um campo; assim se dá a introdução da noção de campo, muito importante para a filosofia posterior de Merleau-Ponty. Em Signos, Merleau-Ponty diferencia 
um advento de um evento. Um advento estabelece o campo no qual ocorrem os eventos. O advento não é uma essência atemporal, mas não está, em termos estritos, localizado em um ponto particular no espaço e no tempo. Ele preside uma forma de vida; ele fornece uma estrutura para a produção de sentido imbuída de autoridade.

Em seus cursos de 1954 e 1955 no Collège de France, respectivamente intitulados L'institution e La passivité, encontramos outra dimensão de passividade na própria atividade de conferir significado. Em seu prefácio aos cursos em versão publicada, Lefort argumenta que doamos sentido ao que nos aparece apenas ao respondermos a uma solicitação de fora e que, ao fazê-lo, seguimos uma orientação que nos é imposta por um determinado campo, campo esse que envolve níveis e dimensóes, e que abre horizontes... "[a] vida da percepção nos ensina que se atribuímos sentido a tudo o que nos acontece, isso é feito desde o momento de nosso nascimento por meio da experiência de algo irredutivelmente anterior a uma exterioridade irredutível, e a uma alteridade que é também ela irredutível" (Lefort, 2010, p. 9).

Em nome da brevidade, náo irei me ocupar, aqui, com o modo como isso se desenrola no desenvolvimento da filosofia política de Merleau-Ponty. No segmento final de Humanismo e terror, no entanto, ele chega a uma posição não muito diferente da de Pippin. Rejeitarmos o Marxismo - caracterizado não como uma filosofia da história, mas como a filosofia da história - significa necessariamente "enterrarmos a razão na história"? Teríamos nós chegado a um relativismo de estilo rortyano, para o qual a história é tão somente uma maldita coisa após a outra? A resposta de Pippin, como vimos, é tentar reter uma "versão fraca" da teleologia. A resposta de Merleau-Ponty é rejeitar a teleologia e buscar domínios limitados de significado, campos de significado, "tufos de significaçóes, arborização de sentidos" (MerleauPonty, 2007, p. 127). Muito da filosofia política de Merleau-Ponty, inclusive As Aventuras da Dialética, consistirá em contestar a posição de que haveria equivalência entre contingência e irracionalidade. Ele buscará a racionalidade dentro da contingência. Dentro de determinado campo instituído, também ele próprio contingente, existe certa racionalidade.

No curso de 1954 no Collège de France intitulado "Materiais para uma teoria da história", ele escreveu: "Há [...], em Weber, o esboço de uma fenomenologia das escolhas históricas que descobre os núcleos inteligíveis em torno dos quais se instala o infinito detalhamento dos fatos" (Id., 2000, p. 4). Ele descobriria uma concepção de sentido histórico, na obra de Weber, que não é totalizante e não é o desfecho da história humana como um todo. Como tratada por Max Weber, a ética protestante é uma matriz inteligível. Merleau-Ponty vê Weber como um praticante daquilo a que, em $O$ visivel e o invisivel, ele chama hiper-reflexão, isto é, uma reflexão que é consciente de seu próprio caráter situado e secundário. Uma tal reflexão percebe que não 
pode retornar às origens do significado, a uma pura espontaneidade da consciência capaz de transitar entre o constituído e o constituinte de maneira semelhante a como se poderia caminhar tanto na direção que leva a Notre Dame a partir da Place de L'Étoile quanto na direção que leva à Place de L'Étoile a partir de Notre Dame.

III.

Na primeira parte deste texto, apresentei um breve - mas, espero, não impreciso esboço da concepção de Modernidade de Pippin e de como a radicalização de Kant efetuada por Hegel é a filosofia mais adequada a ela. Em seguida, extraí da filosofia de Merleau-Ponty alguns dos temas que, argumento, contestam a noção de subjetividade como espontaneidade que Pippin retém de Kant: as concepçóes merleaupontianas de instituição, hiper-reflexão e assim por diante. Agora, volto-me à filosofia de Lefort a fim de mostrar como sua apropriaçáo dessa dimensão do pensamento de Merleau-Ponty produz uma reflexão filosófica mais capaz de compreender a época moderna, sem qualquer compromisso com teleologia ou teologia - nem mesmo com aquele fantasma da teleologia de Hegel que Pippin deseja manter.

O pensamento de Lefort sobre nossa modernidade política, e sobre a Modernidade em geral, torna inteligíveis tanto sua continuidade quanto sua descontinuidade com o passado. Comecemos com um esboço de sua interpretação de Maquiavel. Ele vê o florentino não como alguém que diz algo de novo sobre um tema antigo, mas que reage a um novo fenômeno, a saber, o tornar-se anônimo do poder político. Lefort detecta muita dissimulação na obra de Maquiavel, não apenas como proteção contra a repressão, como defenderia Leo Strauss, mas principalmente de modo a não assustar seus leitores, já que fala de algo que é tão radicalmente novo. Dentro do regime político teológico cristáo, o poder do Príncipe é investido em seu corpo através do sacramento da coroação, como figurado notavelmente no filme Jeanne la pucelle (1994), de Jacques Rivette. O corpo do Príncipe é duplo, um tema ao qual retornaremos. O Príncipe mantém um relacionamento diferente com Deus, relacionamento esse que é a base de sua legitimidade.

Nem Lefort nem Maquiavel veem a perda de legitimidade divina como manancial de niilismo político, como defenderia Leo Strauss. Como argumenta Lefort, a "crítica da tradição [desenvolvida por Maquiavel] precisa oscilar entre dois polos. Ele dedica seus esforços a simultaneamente desacreditar a concepção clássica e cristã do estado e condenar a política sem princípios dos pseudo-sábios de Florença. Em lugar de um suposto conhecimento de filosofia e religião, ele coloca uma espécie de não-saber, de modo tal que sua análise do poder parece, por um momento, suspensa sobre o vazio" (Lefort, 1972, p. 400). Onde a filosofia clássica encontrou um fundamento para a política - na Natureza ou na Vontade de Deus -, Maquiavel encontra um vazio. A 
perda do Direito Divino dá origem à política "propriamente dita", uma que é baseada no conflito e implica, como diria Hannah Arendt, uma pluralidade irredutível. Ela não nos leva, no entanto, a uma guerra hobbesiana de cada um contra todos: por meio da imagem do Príncipe, lócus do poder, o conflito é institucionalizado. Maquiavel nos conta que em toda institucionalidade política há duas disposiçóes: o desejo de governar e oprimir e o desejo de não ser governado ou oprimido. Maquiavel aconselha o Príncipe a não fazer uma aliança com os grandes, os poderosos, pois eles o veriam como um dos seus, alguém que, como eles, busca o poder. Sua aliança deve ser com o povo. O povo deseja que o Príncipe governe porque seu governo se afasta dos grandes, de sua pretensão de comandar e oprimir. Esse é o caso porque o Príncipe comanda tanto o povo quanto os grandes. O Príncipe ocupa a posição de um Terceiro e, portanto, está acima do conflito entre os poderosos e o povo.

A posição do Terceiro não tem fundamento natural ou teológico. Ela é constituída pela troca simbólica do povo com o Príncipe. Ela está, como diz Lefort, suspensa sobre um vazio. O povo apoia o Príncipe devido a seu desejo de não ser oprimido, mas será oprimido pelo Príncipe, em seu turno. Sua opressão, no entanto, será de natureza diferente da que é exercida pelos grandes, já que neles o povo reconhece seu adversário natural, o Outro que os constitui como objeto imediato de seu desejo. Em Lefort, "natural" denota o que não é politicamente instituído ou institucionalmente mediado. O povo deseja náo ser o objeto do poder; embora esse desejo não seja satisfeito, ele obtém a melhor opçáo possível, dadas as circunstâncias. O poder é mediado e o conflito é institucionalizado. O poder é inserido, mas não no corpo do Príncipe: "[O] príncipe é ele mesmo determinado em relação à posição que ocupa" (Ibid., p. 348). Ele não é o demiurgo da história. Na Modernidade, o poder político se tornou anônimo e encontramos pela primeira vez o tema da desencarnação, cuja importância para a concepção de Modernidade de Lefort é expressiva. A leitura que Lefort empreende de Maquiavel e sua obra, embora ainda marxista, antecipa sua reflexão posterior sobre os fenômenos da democracia moderna e do totalitarismo. Ele não oferece nenhuma grande narrativa, nenhuma estória sobre como finalmente conseguimos reconhecer o que vínhamos fazendo o tempo todo. Como veremos abaixo, seus pensamentos sobre a Modernidade têm por enquadramento um contexto ontológico. No já citado Le travail de l'œuvre Machiavel, Lefort escreve: "As fronteiras da filosofia política não são elas mesmas políticas" (Ibid., p. 344). Ele começa sua reflexão no aqui-e-agora, em sentido amplo, de nossa modernidade política com uma consideraçáo sobre as Revoluçóes Francesa e Americana. O abandono do Ancien Régime é, para Lefort, mais do que uma mudança de governo: trata-se de uma mudança de formas de vida, uma mudança na maneira de se produzir sentido, uma mudança, enfim, em nosso relacionamento com o mundo e com a morte. 
Em relação à noção de Modernidade como ruptura com o passado, Lefort está de acordo com o Kant de "Resposta à pergunta: Que é 'Esclarecimento'?” e, como Hegel, ainda assim defenderá uma continuidade com o passado. Porém, diferentemente do que ocorre em Hegel - mesmo na interpretação de Pippin -, essa continuidade não será enquadrada no que poderia ser lido como uma narrativa teleológica. Para Lefort, a Revolução Francesa é um advento, no sentido que MerleauPonty conferiu ao termo em Signos. Como evidenciam seus primeiros escritos sobre antropologia, Lefort via as sociedades pré-modernas como sociedades cuja estrutura simbólica fora fundada em "um outro lugar". Os marcadores simbólicos são a estrutura: lei, poder e conhecimento. Eles estão localizados em um outro lugar, são um invisível massivamente afirmado. Essas sociedades pré-modernas não carecem de história, como afirmaram Hegel e Husserl; elas rejeitam positivamente a história, um modo de temporalizaçáo que engendra uma narrativa linear. Lefort cita o trabalho de antropólogos para mostrar como essa rejeição da linearidade funciona em sociedades pré-modernas. Entretanto, o teológico-político cristão da Europa náo pode simplesmente rejeitar a história; isso contradiria dogmas cristáos como, por exemplo, o nascimento de Cristo, a criaçáo do mundo no tempo e assim por diante. Disso a censura a uma concepção circular do tempo, denunciada por Agostinho como "dança perversa em círculos" (Manuel, 1965, p. 3).

Com base no trabalho de François Guizot, bem como no de Ernest Kantorowicz, em particular Os dois corpos do rei, Lefort mostra como, após séculos de conflito entre Igreja e Estado, a monarquia europeia representaria sua legitimidade divina por meio da imagem da duplicação do corpo do Rei, corpo de Natureza e corpo de Graça. A monarquia europeia não é, ainda assim, uma teocracia: o Rei não é divino em seu corpo natural. Porém, através da relação de seu corpo de Graça com Deus, ele encarnará a nação. "Luís, Rei da França, pela vontade de Deus". O corpo do Rei tem em si uma relação com um outro lugar, uma dimensão de transcendência. A revoluçáo apagará a figura do Rei, seu corpo. Para Lefort, no entanto, ela mantém uma relação com a transcendência, uma dimensão de transcendência, embora se trate de uma transcendência que náo pode ser encarnada ou representada. $O$ lugar da transcendência permanece, mas permanece vazio. Um regime democrático deriva sua legitimidade do povo; porém, é essencial para Lefort que o povo permaneça indeterminado e indefinido. Essa natureza indefinida do povo remove Lefort de qualquer noçáo de populismo. Deve-se enfatizar, ademais, que, para Lefort, a transiçáo do Ancien Régime para a democracia não é efetuada por meio do conceito de contrato social.

Lefort estabelece distinção entre o Político e a Política. O discurso sobre o Político é centrado na natureza do regime. Aqui, Lefort reencontra a filosofia política clássica, onde a questão é determinar quais são os diferentes tipos de regime e qual 
deles é o melhor. A Política, por sua vez, concerne a quem exercerá o poder em nome do povo e a que leis deverão ser aprovadas. Para Lefort, nenhuma sociedade é integral, nenhuma sociedade está em paz consigo mesma. A identidade do corpo político, como a do corpo vivido, é constituída sobre uma lacuna, um écart. Sua identidade é frágil. Em sociedades pré-modernas, essa não identidade da sociedade consigo mesma é representada pela relação com um outro mundo, com um outro lugar; na pré-modernidade cristã, pela referência a Deus; na democracia moderna, pela referência a um lugar vazio. Segundo Lefort, cada regime leva a efeito uma maneira própria de produzir sentido, mise en sense, e de representar a si mesmo, mise en scène. Lefort, diferentemente de Leo Strauss e, até certo ponto, de Hannah Arendt, não concebe a Modernidade em termos de perda. A Modernidade é uma outra maneira de organizarmos nossa não identidade, que é parte da condição de finitude humana. Ele começa seu artigo seminal "Permanência do teológico-político?", com uma citação da Enciclopédia de Hegel: "Pode-se considerar o erro monstruoso do nosso tempo querer considerar esses inseparáveis [a religião e a política] como separáveis entre si, ou mesmo como mutuamente indiferentes" (Lefort, 1991, p. 250). A subscrição de Lefort a essa citação é ambígua. Ele não concorda com Hegel no que toca à relação entre religião e filosofia, a religião como uma representação pictórica do que a filosofia traria ao conceito. Antes, trata-se de serem a filosofia e a religião duas interpretaçóes diferentes e mutuamente exclusivas de uma mesma experiência, a experiência da finitude humana; nossa diferença de nós mesmos; nosso exílio de nós mesmos, uma identidade constituída através da diferença, através de um écart. Ele argumenta que o que a filosofia descobre na religiáo quando permanece fiel à sua inspiraçáo é um modo de prolongar ou dramatizar as relaçóes que os humanos estabelecem com algo que ultrapassa o tempo e o espaço empíricos em cujo interior eles se relacionam uns com os outros. Nesse importante ensaio, ele escreve: "Uma vez que reconheçamos que a humanidade se abre a si mesma ao ser mantida em uma abertura que ela mesma não cria, temos de aceitar que a mudança na religião não dá apenas a ler os signos de uma invenção humana do divino, mas sim a de um deciframento do divino ou, sob a aparência do divino, do excesso do ser sobre o aparecer" (Ibid., p. 287).

$\mathrm{Na}$ citação acima, o que Lefort tem em mente ao se referir à "mudança na religiáo" é o advento da Modernidade. Nas sociedades pré-modernas, a humanidade vivenciou sua própria não coincidência consigo mesma, que interpretou como uma relação com um outro mundo, um mundo habitado por Deus, pela Deusa, por deuses e assim por diante. O conteúdo doutrinário da religião é uma dramatização dessa experiência de não coincidência. Desse modo, como no pensamento de Freud e Feuerbach, a representação de Deus ou dos deuses é uma projeção humana. O que 
não é explicável como projeção humana, entretanto, é a experiência de sermos entregues a nós mesmos com base em uma alteridade fundamental. Por que falar em alteridade fundamental? Penso se tratar de nossa inserção na Natureza, concebida, a Natureza, como desprovida de finalidade. Creio que Lefort estaria de acordo com Bernard Williams quando este diz que estamos mais perto dos gregos do que nunca, já que, como eles, nós percebemos que o cosmos não foi feito para nós, nem nós para o cosmos, que é a um só tempo fundamento de nossa existência e abismo.

Ao nos descobrirmos seres naturais, percebemo-nos no interior da história - não em sua origem, mas, como diz Kafka, em "um ponto qualquer situado no meio". A Modernidade, para Lefort, não é nossa chegada, por fim, a nós mesmos, mas apenas mais uma época histórica, tão contingente quanto todas as outras. Como MerleauPonty, ele tem uma elevada tolerância à contingência; ele era partidário, afinal, de uma lógica interna à contingência. A instituição política por excelência da Modernidade, a democracia - como seu gêmeo maligno, o totalitarismo -, é contingente. Ela é um teste, uma provação, um batismo de fogo; ou, como diria Hannah Arendt, ela não tem balaústres, carece de fundamento natural ou divino. Esse conceito de democracia está relacionado com sua compreensão, passível de explicação, do totalitarismo como inelutavelmente vinculado à democracia. $\mathrm{O}$ impulso totalitário tem por base o frenesi produzido pela percepção de que o lugar vazio náo é apenas simbolicamente vazio, mas realmente vazio, e de que o simbólico caiu no Real. Sem uma referência à transcendência, o projeto totalitário é o de preencher o espaço vazio com um líder que encarne o povo. Não aquele povo indefinido do qual a democracia deriva sua legitimidade, mas um povo de contornos definidos: "O povo como Um": pessoas brancas, estadunidenses "de verdade" e assim por diante. Embora a Modernidade não seja, para Lefort, a portadora do projeto universal, ela também não está fechada em si mesma, restrita a limites determinados. Ela abre um leque de possibilidades. No entanto, não há garantia de que essas possibilidades seráo aproveitadas. É mais do que claro que, para alguns, a perda do fundamento natural ou religioso é um preço alto demais a se pagar pela liberdade que torna possível.

\section{Referências bibliográficas}

Bernet, R. (1993). “The Subject in Nature: Reflections on Merleau-Ponty's Phenomenology of Perception". In: Burke, P.; Van Der Veken, J. (orgs.). MerleauPonty in Contemporary Perspective. Dordrecht: Springer, p. 53-68.

Gauchet, M. (1997). The Disenchantment of the World: A Political History of Religion. Trad. Oscar Burge. Princeton: Princeton University Press. 
Hegel, G. W. F. (2003) Fenomenologia do Espirito. Trad. Paulo Meneses et al. Petrópolis: Vozes.

Kant, I. (1985). "Resposta à pergunta: Que é 'Esclarecimento'?" Trad. Raimundo Vier e Floriano de Sousa Fernandes. In: Textos seletos. Petrópolis: Vozes, p. 100117.

Vozes.

(2019). Crítica da razão pura. Trad. Fernando Costa Mattos. Petrópolis:

Kantorowicz, E. H. (1998). Os dois corpos do rei: um estudo sobre teologia política medieval. Trad. Cid Knipel Moreira. São Paulo: Companhia das Letras.

Lefort, C. (1972). Le travail de l'ouvre Machiavel. Paris: Gallimard.

(1991). “Permanência do teológico-político?” In: Pensando o político: ensaios sobre democracia, revolução e liberdade. Trad. Eliana M. Souza. Sáo Paulo: Paz e Terra, p. 249-296.

Löwith, K. (1949). Meaning in History: the Theological Implications of the Philosophy of History. Chicago: The University of Chicago Press.

Manuel, F. E. (1965). Shapes of Philosophical History. Stanford: Stanford University Press.

Merleau-Ponty, M. (1968). Humanismo e terror: ensaio sobre o problema comunista. Trad. Naume Ladosky. Rio de Janeiro: Tempo Brasileiro.

(1971). O visivel e o invisivel. Trad. José Artur Gianotti e Armando Mora d'Oliveira. São Paulo: Perspectiva.

(1975). A estrutura do comportamento. Trad. José de Anchieta Corrêa. Belo Horizonte: Interlivros.

(1991). Signos. Trad. Maria Ermantina Galvão Gomes Pereira. São Paulo: Martins Fontes.

(1999). Fenomenologia da Percepção. Trad. Carlos Alberto Ribeiro de Moura. São Paulo: Martins Fontes.

(2000). Materiais para uma teoria da história [1954]. Trad. Monclar

Valverde. Disponível em: <https:/filosoficabiblioteca.files.wordpress.com/2013/10/merleau-ponty-materiais-para-uma-teoria-da-historia-merleau-ponty.pdf>. Edição digital. Acessado em 19 de fevereiro de 2020.

. (2006). As aventuras da dialética. Trad. Claudia Berliner. Sáo Paulo: Martins Fontes.

(2007). A prosa do mundo. Trad. Paulo Neves. São Paulo: Cosac Naify.

(2010). L'institution. La passivité. Notes de cours au Collège de France (1954-1955). Paris: Belin.

Pinkard, T. (2017). Does History Make Sense? Hegel on the Historical Shapes of Justice. Cambridge, Mass.; London: Harvard University Press. 
Pippin, R. B. (1989). Hegel's Idealism: The Satisfactions of Self-Consciousness. Cambridge; New York: Cambridge University Press.

(1999). Modernism as a Philosophical Problem: On the Dissatisfactions of European High Culture. Oxford: Blackwell. (2011). Hegel on Self-Consciousness: Desire and Death in the Phenomenology of Spirit. Princeton; Oxford: Princeton University Press.

Sartre, J.-P. (1997). O ser e o nada: ensaio de ontologia fenomenológica. Trad. Paulo Perdigão. Petrópolis: Vozes.

Saussure, F. de. (1977). Curso de linguistica geral. Trad. Antônio Chelini, José Paulo Paes e lzidoro Blikstein. São Paulo: Cultrix. 